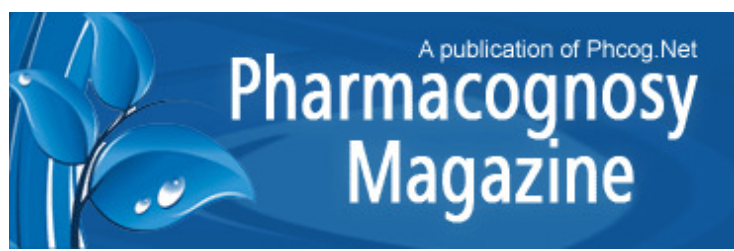

ORIGINAL ARTICLE
Year : 2017 | Volume : 13 | Issue : 50 | Page : 375--379

\title{
Novel approaches to extraction methods in recovery of capsaicin from habanero pepper (CNPH 15.192)
}

Frederico S Martins ${ }^{1}$, Leonardo L Borges ${ }^{2}$, Claudia S. C. Ribeiro ${ }^{3}$, Francisco J. B. Reifschneider ${ }^{3}$, Edemilson C Conceição ${ }^{4}$,

1 Universidade de São Paulo, Faculdade de Ciências Farmacêuticas de Ribeirão Preto, Brazil

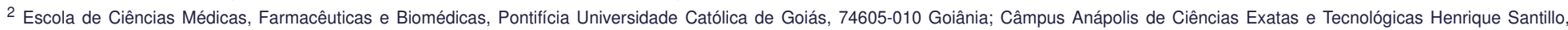
Universidade Estadual de Goiás, BR-153, Km 98, 75001-970 Anápolis, GO, Brazil

${ }^{3}$ Embrapa Hortaliças, Brazil

${ }^{4}$ Universidade Federal de Goiás, Faculdade de Farmácia, Brazil

\section{Correspondence Address:}

Frederico S Martins

Universidade de São Paulo, Faculdade de Ciências Farmacêuticas de Ribeirão Preto- Avenida do Café, s/n Ribeirão Preto - SP CEP Brazil

\section{Abstract}

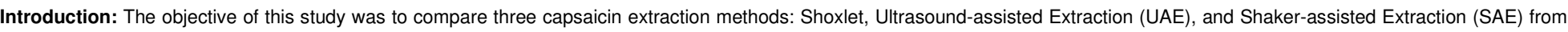

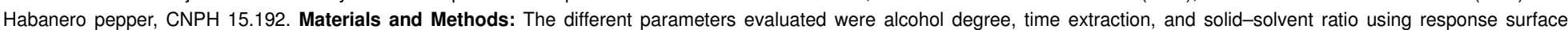

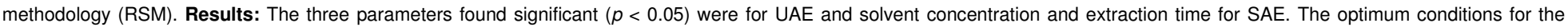

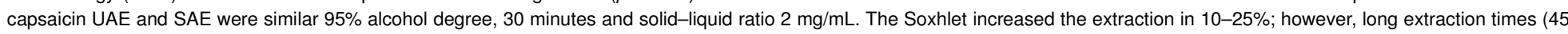

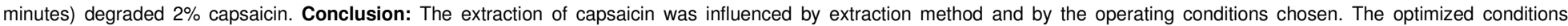

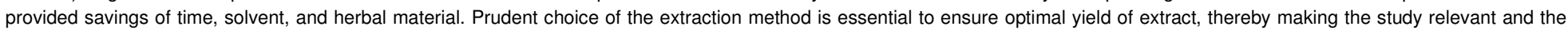

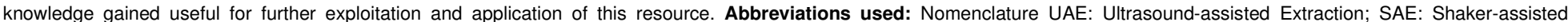
Extraction.

How to cite this article:

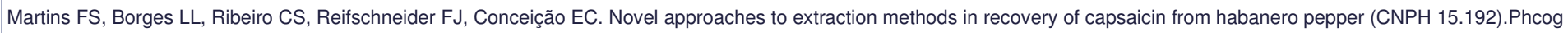
Mag 2017;13:375-379

How to cite this URL:

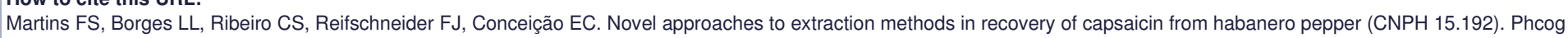
Mag [serial online] 2017 [cited 2017 Nov 27 ];13:375-379

Available from: http://www.phcog.com/text.asp?2017/13/50/375/210127

\section{Full Text}

Summary

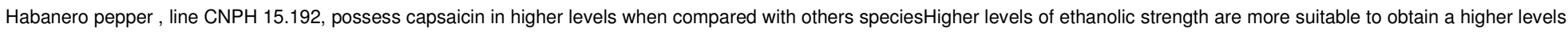
of capsaicinBox-Behnken design indicates to be useful to explore the best conditions of ultrasound assisted extraction of capsaicin.

\section{Introduction}

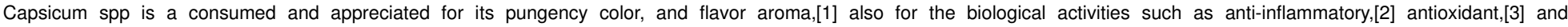

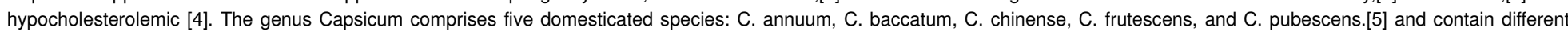
amounts of capsaicinoids, carotenoids, vitamins, and flavonoids.

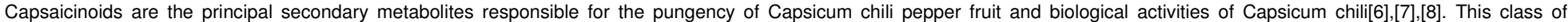
compounds possesses more than 50 capsaicinoids, which can be identified and quantified by HPLC, HPLC-MS, GC and GC-MS.[7]

Embrapa vegetable crops have an important Capsicum breeding program that has focused on the development of habanero-type cultivars (C. chinense, line CNPH 15.192).

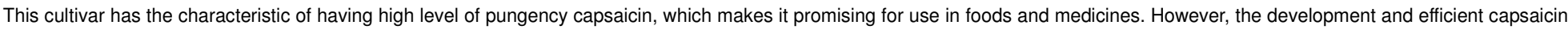
extraction method for pharmaceutical and alimentary industry depends on method, herbal material, and optimization technique.[9]

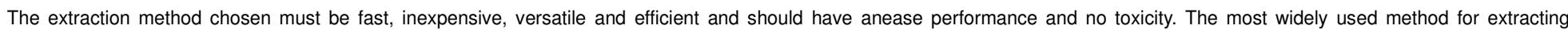
capsaicin is based on extraction with hexane, which is very toxic and produces residual solvent.[10],[11],[12]

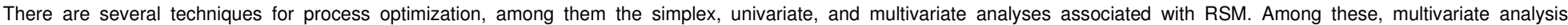
associated with RSM is efficient due to its versatility, ability to assess multiple factors, ease of performance, and robustness.[13],[14]

Thus, the present study aimed to evaluate and optimize different capsaicin extraction methods, prioritizing operational versatility and low toxicity solvent extractors.

\section{Materials and Methods}




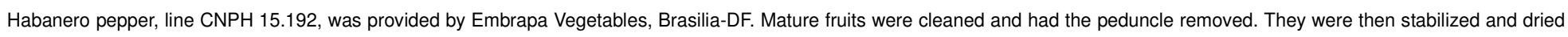
in an oven with forced air circulation at $40^{\circ} \mathrm{C}$ for 48 hours. Dried fruit were ground in a knife mill TE- 625 (Tecnal Ltda, Piracicaba, SP, Brazil) and the powder was stored at $-4{ }^{\circ} \mathrm{C}$.

HPLC analysis

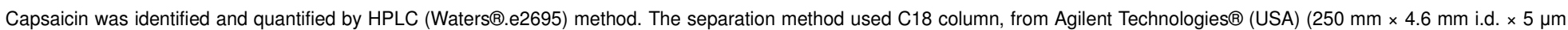

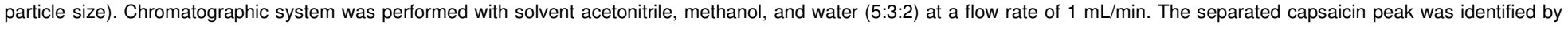
comparing the individual standard with the retention time and the UV $229 \mathrm{~nm}$ spectra. The methodology was validated in accordance to.[15]

Extraction of Capsaicin

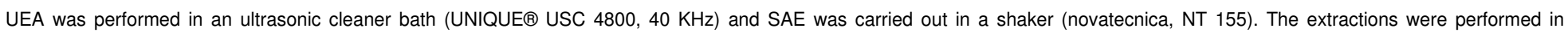
volumetric flasks $(5 \mathrm{~mL})$ with different hydroethanolic mixtures.

Evaluation of Degradation of Capsaicin by UEA, SAE, and Soxhlet Extraction

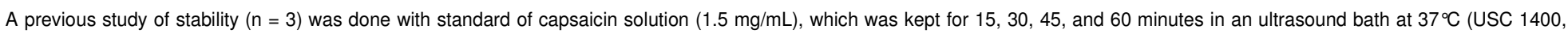

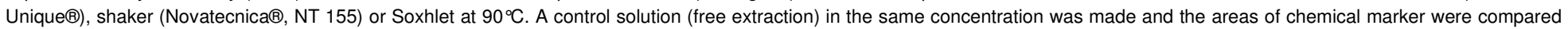
by HPLC.

Capsaicin Content

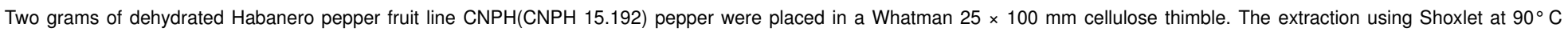

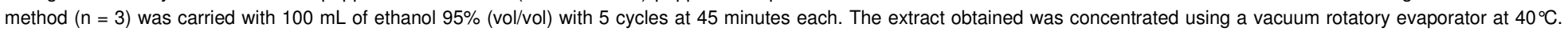
The dried extract was analyzed by HPLC.

\section{Experimental design}

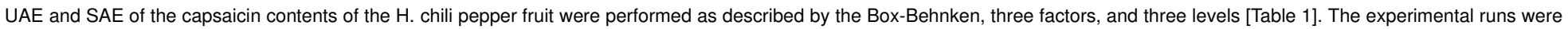

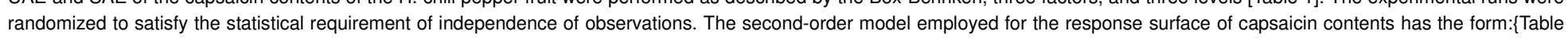
$1\}$

[INLINE:1]

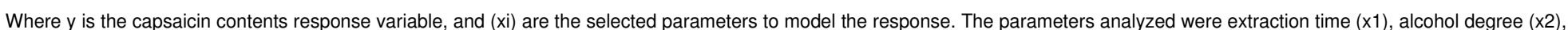

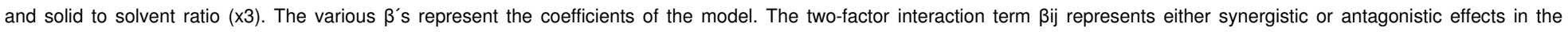
capsaicin extraction process. All the calculations were carried out using Design-Expert@version 7.0.0.[16]

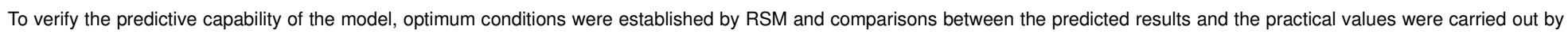
experimental repetition using presumed optimal conditions. The Soxhlet extraction was performed with $2 \mathrm{mg} / \mathrm{mL}$ of herbal material by $30 \mathrm{minutes}$, with ethanol $95 \%$.

\section{Results and Discussion}

The system suitability parameters were in accordance with the literature specifications [Table 2]. The HPLC method proved to be capable of providing data of acceptable quality, performing the selectivity test, linearity, precision, and accuracy. [Table 3] highlights the values obtained from method validation; the calibration curves showed a linear response (0.5-40 $\mu \mathrm{g} / \mathrm{mL})$, obtaining correlation coefficients $(\mathrm{r}) 0.999$. The LOD $(0.22 \mu \mathrm{g} / \mathrm{mL})$ and LOQ $(0.34 \mu \mathrm{g} / \mathrm{mL})$ showed that the present method is adequate and has the sensitivity to detect and quantify of capsaicin from H. pepper (CNPH 15.192). \{Table 2\}\{Table 3\}

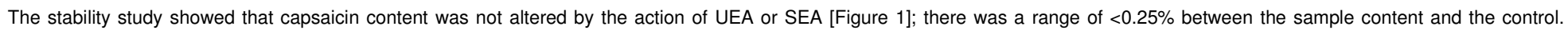
However, the extraction by Soxhlet degraded $2 \%$ of capsaicin after 45 minutes of extraction.\{Figure 1 \}

The total capsaicin content extracted by Soxhlet (exhaustion process) showed that $\mathrm{H}$. pepper has $2.2 \%(22.0 \mathrm{mg} / \mathrm{g})$ of capsaicin. The UEA recovered $90.7 \%(14.2-19.9 \mathrm{mg} / \mathrm{g})$ and SAE $76.1 \%(8.3-16.9 \mathrm{mg} / \mathrm{g})$ [Table 4]. The higher extraction yield obtained by the Soxhlet is attributed to high extraction time, temperature, and drug solvent ratio. These factors increase the solubility of capsaicin. This method demanded a long extraction time (225 minutes), a large volume of solvent (500 $\mathrm{mL}$ ) and degraded the sample. Although UEA and SEA extracted less capsaicin (9.3-23.9\% less) they did save $86 \%$ of extraction time and $99 \%$ of solvent.\{Table 4$\}$

The UEA recovered $15-41.5 \%$ more capsaicin than the SEA method [Table 4]. The higher extraction yield obtained by the UEA is attributed to the effects of acoustic cavitations in the solvent, which were produced by ultrasonic waves. The waves also exert a mechanical effect, increasing the penetration of the solvent into the herbal matrix and the contact surface between the solid and liquid phases.[17],[18],[19] The RSM showed that the X1.X2.X3, X1.X2 and X2.X3 had significant $(p<0.05)$ effect on UEA process and X2 and X1.X2 on SAE [Table 5]. [Figure 2]a, [Figure 2]b, and [Figure 3] show that high level of extraction time (X1), alcohol degree (X2), and drug solvent ratio (X3) increase the extraction of capsaicin in both the extraction methods.\{Table 5\}\{Figure 2\}\{Figure 3\}

The optimal theoretical extraction parameters for capsaicin (2.0\% to UAE and $1.70 \%$ to SEA) calculated by RSM were similar in both methods of extraction, 30 minutes of extraction time, $2 \mathrm{mg} / \mathrm{mL}$ of herbal material, and $95 \%$ of alcohol degree [Figure 2] and [Figure 3].

Tests were conducted again in triplicate and showed that the capsaicin contents obtained from extraction under optimal conditions were $2.09+0.05 \%$ wt/wt $(n=3)$ to UEA and $1.71 \pm$ $0.06 \% \mathrm{wt} / \mathrm{wt}(\mathrm{n}=3)$ to SEA. The good correlation between the theoretical results and the reexamined values confirmed that the response model represented the expected optimization well (Equation 1 and Equation 2, uncoded values).

[INLINE:2]

The choice of extraction method must be made carefully, as use of harmful solvents, high temperatures, and waste material need to be avoided. Currently, the use of harmful solvents in the manufacture of food and medicine has been strictly controlled by health agencies, including the FDA United States Food and Drug Administration (USFDA), the Brazilian Health Surveillance Agency (ANVISA), and the European Union Agency (EMA). With the increasing demand for drug and food, wastage of natural resources should be avoided. Advanced techniques have been used in optimization processes, helping to prevent wastage and increasing the quality.[20],[21]

The UAE has many advantages, however, its use for extraction of bioactive compounds should be chosen carefully. During the formation of cavity bubbles, there is a momentary increase in temperature $(550 \mathrm{oC})$ and pressure $(550 \mathrm{~atm})$. This may accelerate the degradation of the compounds of interest, forming low molecular weight.[22],[23],[24] 


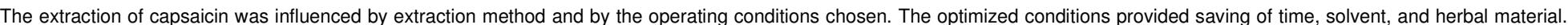

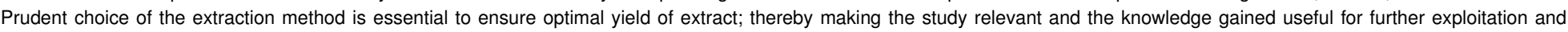
application of this resource.

Acknowledgements

The authors gratefully acknowledge the CAPES, CNPq, and EMBRAPA

Financial support and sponsorship

CNPq and CAPES

Conflict of Interest

None

\section{References}

1 Aranoff SL, Pearson DR, Okun DT, Lane CR, Williamson IA, Pinkert DA, Monitoring of U. S. Imports of Peppers. US. International Trade Commission 2008:4:332.

Demirbilek S, Ersoy MO, Demirbilek S, Karaman A, Gürbüz N, Bayraktar N, Small-dose capsaicin reduces systemic inflammatory responses in septic rats. Anesthesia and Analgesia 2004;99:1501-7.

Menichini F, Tundis R, Bonesi M, Loizzo M, Conforti F, Statti G, The influence of fruit ripening on the phytochemical content and biological activity of Capsicum chinense Jacq. cv Habanero. Food Chemistry 2009;114:553-60.

Alvarez-Parrilla E, de la Rosa LA, Amarowicz R, Shahidi F, Protective effect of fresh and processed Jalapeño and Serrano peppers against food lipid and human LDL cholesterol oxidation. Food Chemistry 2012;133:827-34.

$5 \quad$ Pickersgill B, Genetic resources and breeding of Capsicum spp. Euphytica 1997;96:129-33.

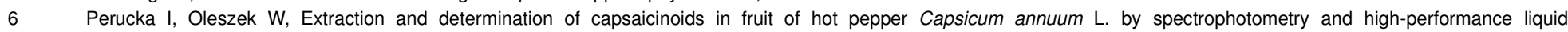
chromatography. Food Chemistry 2000;71:287-91.

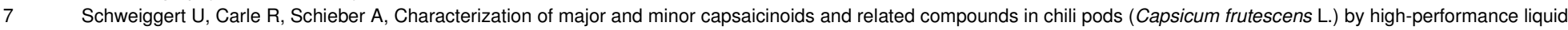
chromatography/atmospheric pressure chemical ionization mass spectrometry. Analytica Chimica Acta 2006;557:236-44.

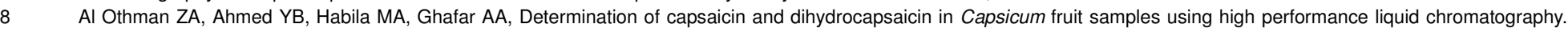
Molecules 2011;16:8919-29.

Chinn MS, Sharma-Shivappa RR, Cotter JL, Solvent extraction and quantification of capsaicinoids from Capsicum chinense. Food and Bioproducts Processing 2011;89:340-5. Gao L, Mazza G, Extraction of anthocyanin pigments from purple sunflower hulls. Journal of Food Science 1996;61:600-3.

Martins FSM, Cardoso EC, Evaluation of extraction method on the chemical composition in Apeiba tibourbou Aubl s extracts. Pharmacognosy Magazine 2015;11:368-73.

Martins FS, Conceição EC, Bandeira ES, Costa RMR, Silva JOC, The effects of extraction method on recovery rutin from Calendula officinalis L (Asteraceae). Pharmacognosy Magazine 2014;10:569-73

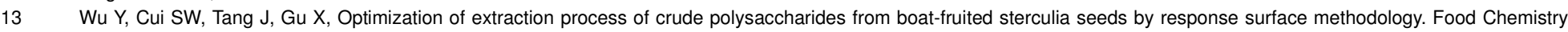
2007;105:1599-605.

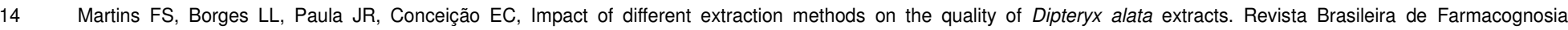
2013;23:521-6.

USP (2011) United States Pharmacopeial Convention. Rockville.

Stat-Ease IM, (2005) Design-ExpertMinneapolis, MN, USA, 70.0

Zhang H-F, Yang X-H, Zhao L-D, Wang Y, Ultrasonic-assisted extraction of epimedin C from fresh leaves of Epimedium and extraction mechanism. Innovative Food Science \& Emerging Technologies 2009;10:54-60.

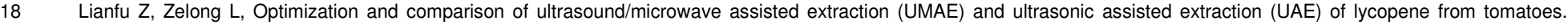
Ultrasonics Sonochemistry 2008;15:731-7.

Riera E, Gallego-Juárez JA, Mason TJ, Airborne ultrasound for the precipitation of smokes and powders and the destruction of foams. Ultrasonics Sonochemistry 2006;13:107-16

Huang W, Xue A, Niu H, Jia Z, Wang JW, Optimised ultrasonic-assisted extraction of flavonoids from Folium eucommiae and evaluation of antioxidant activity in multi-test systems in vitro. Food Chemistry 2009;114:1147-54

(

Gonze E, Fourel L, Gonthier Y, Boldo P, Bernis A, Wastewater pretreatment with ultrasonic irradiation to reduce toxicity. Chemical Engineering Journal 1999;73:93-100.

Schläfer O, Onyeche T, Bormann H, Schröder C, Sievers M, Ultrasound stimulation of micro-organisms for enhanced biodegradation. Ultrasonics 2002;40:25-9.

Yosef E, Ben-Ghedalia D, Miron J, Huttermann A, Majcherczyk A, Milstein O, Characterization of some cell wall components of untreated and ozone-treated cotton stalks. Journal of Agricultural and Food Chemistry 1994;42:86-90. 